\title{
BILATERAL STUDIES OF CEREBRAL OXYGEN UPTAKE IN YOUNG AND AGED NORMAL SUBJECTS AND IN PA- TIENTS WITH ORGANIC DEMENTIA
}

\author{
By N. A. LASSEN,* I. FEINBERG ANd M. H. LANE \\ (From the Laboratory of Clinical Science, National Institute of Mental Health, National \\ Institutes of Health, Bethesda, Md.)
}

(Submitted for publication April 20, 1959; accepted October 23, 1959)

A relation between reduced cerebral oxygen uptake $\left(\mathrm{CMRO}_{2}\right)$, measured by the inert gas method of Kety and Schmidt (1), and impaired mental function has been described in many clinical conditions. In patients with chronic degenerative cerebral diseases, such a relationship was first noted by Freyhan, Woodford and Kety in their study of aged psychotic patients (2). This finding has since been confirmed by many investigators studying related clinical problems (3-7). In general, a reduction of $\mathrm{CMRO}_{2}$ was found to be associated with a proportionate reduction of the cerebral blood flow (CBF).

These studies showed considerable overlapping between the values obtained in the deteriorated patients with organic brain disease and in the normal control patients. Recently, Lassen, Munck and Tottey reported a study of $\mathrm{CBF}$ and $\mathrm{CMRO}_{2}$ in middle-aged patients with mental impairment due to diffuse, degenerative brain diseases (8). Compared to normal control subjects of similar age, all patients with organic dementia had subnormal $\mathrm{CMRO}_{2}$, while the CBF showed some degree of overlapping. Furthermore, the degree of reduction of $\mathrm{CMRO}_{2}$ corresponded roughly with the degree of mental deterioration. Psychological tests were employed to assess mental abilities in this study, while the krypton $^{85}$ method was used to measure CBF and $\mathrm{CMRO}_{2}$ bilaterally, employing simultaneous sampling from the right and left internal jugular veins. These relatively minor variations of Kety and Schmidt's method (1) were found to be of value, as they appeared to increase the accuracy of the individual observations.

The demonstration of a close correlation between mental and metabolic deterioration in cere-

* Visiting scientist; present address : Medical Dept. B., Bispebjerg Hospital, Copenhagen N.V., Denmark. bral function is of importance for the understanding of the pathophysiology of organic dementia. Since only 19 subjects were studied by Lassen and associates (8) it was considered desirable to collect more data of this kind. The present report is concerned with clinical and cerebral metabolic data from 25 subjects. The technique and the overall design of the study were similar to that used by Lassen and co-workers. It involved the independent physiological and psychological assessment of the subjects, data being compared only after completion of the entire study.

\section{METHODS}

Cerebral blood flow and oxygen uptake. The inert gas method of Kety and Schmidt (1) was used with the modification described by Lassen and Munck (9). This modification employs a radioactive isotope of krypton $\left(\mathrm{Kr}^{85}\right)$ as the inert gas instead of nitrous oxide.

Each study had a duration of about 16 minutes during which time the subject breathed atmospheric air containing $0.1 \mu \mathrm{c} \mathrm{Kr}^{85}$ per ml. A closed circuit system of $80 \mathrm{~L}$ was used. Blood samples were drawn from indwelling needles in the femoral artery and in both internal jugular veins. Twelve samples of $3 \mathrm{cc}$ each were drawn anaerobically from each source for $\mathrm{Kr}^{80}$ analysis (Figure 1). These 36 samples and a blank sample drawn before $\mathrm{Kr}^{86}$ inhalation were transferred into mica-walled cuvets and the radioactivity measured automatically by 4 Geiger-Müller tubes (9). In order to avoid errors due to variations in erythrocyte sedimentation in the cuvets, the analyses were performed on hemolyzed blood; triton X-100 was used as the hemolytic agent (10). After about 4 minutes of $\mathrm{Kr}^{85}$ inhalation, samples were drawn for manometric $\mathrm{O}_{2}$ and $\mathrm{CO}_{2}$ analyses (11), $\mathrm{pH}$, and spectrophotometric $\mathrm{O}_{2}$ saturation determinations (10). The arterial hematocrit was also measured and was used to calculate the partition coefficient for $\mathrm{Kr}^{85}$ (9).

The calculation of the unilateral (right or left side) values of the cerebral blood flow (CBF) was carried out according to the principle of Kety and Schmidt (1) as modified by Lassen and Munck (9). Extrapolation to infinity was used, but no correction was made for the 


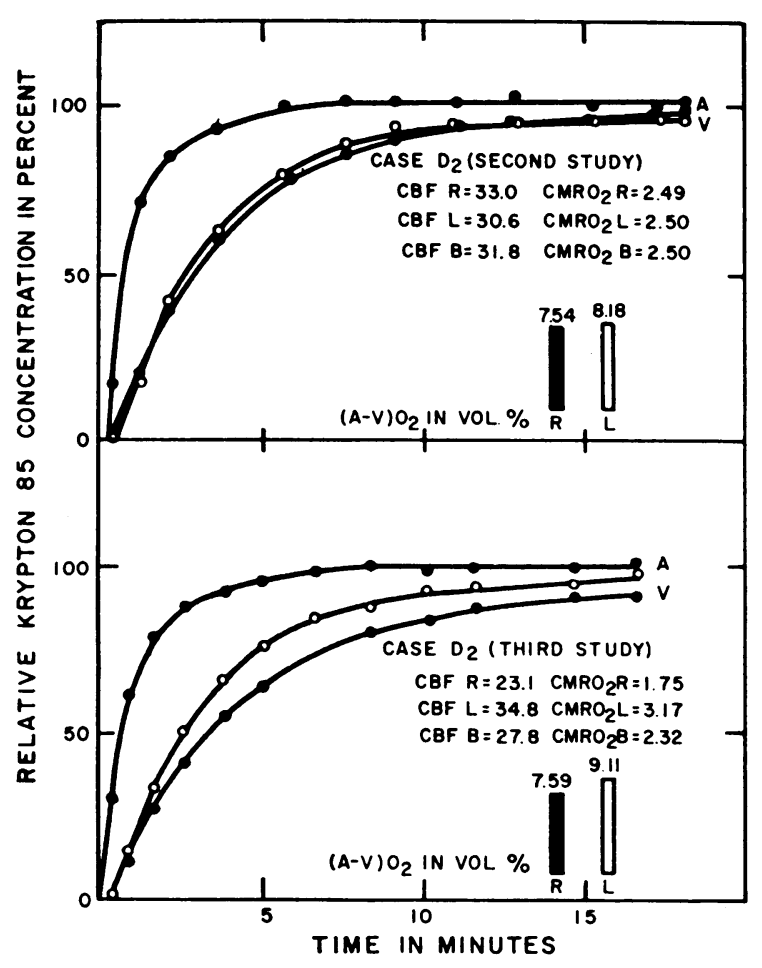

Fig. 1. Two studies in the same subject. An interval of several weeks separated the studies. The open circles represent the venous curves for the left side.

mean circulation time of the brain (9). Though theoretically sound, this correction cannot be made accurately, and it was thought preferable not to use it in the present study. For this reason the infinity values of $\mathrm{CBF}$ and $\mathrm{CMRO}_{2}$ reported in this paper are about 10 per cent lower than those reported by Lassen, Munck and Tottey (8). The unilateral $\mathrm{CBF}$ values also were calculated to an experimental duration of 10 minutes. These values can be compared directly to those obtained by the original nitrous oxide method. The bilateral values were calculated with the assumption that both internal jugular veins carry the same volume of blood. Therefore, the means of the two venous krypton curves and the means of the oxygen contents were used in these calculations.

Clinical data and psychological methods. Twenty-five white male subjects were studied: 11 young normal subjects $(Y)$ of average age 24 years; 5 old normal subjects $(\mathrm{O})$ of average age 72 years; and 9 aged, mentally deteriorated subjects (D) of average age 74 years. The young normal subjects were medical students. They were not examined clinically as it was assumed that none suffered from chronic brain disease of a degree sufficient to impair intelligence.

The two groups of aged subjects were selected and evaluated by a psychiatrist (I.F.) who was not made aware of the circulatory and metabolic data until completion of the entire study. The grouping of these sub- jects as normal or deteriorated mentally was made on the basis of the overall clinical impression: the results obtained by psychometric tests were evaluated in relation to past history, emotional status (cooperativeness) and possible neurological defects. The aged subjects were selected so that the normal aged group was mentally well preserved and alert, whereas the deteriorated subjects all manifested behavioral changes which clearly suggested chronic brain derangement (dementia), with signs of "senility" and confusion (see below).

The examination included: a) psychiatric interview; b) Wechsler's Adult Intelligence Scale (WAIS) (12); c) Raven's Progressive Matrices (13) (including adult and children's forms); $d$ ) Bender Motor Gestalt (14); and $e)$ a digit memory test designed to reveal fluctuations in performance (described in Reference 8). Some clinical data are given in Table $I$ and test scores are listed in Table II. It will be noted that regarding school training and life occupation, no apparent difference existed between the normal and the deteriorated aged subjects, an impression confirmed by the more detailed interviews.

Three of the five mentally normal aged subjects were paid volunteers $\left(\mathrm{O}_{1}, \mathrm{O}_{2}\right.$ and $\left.\mathrm{O}_{4}\right)$, and two were patients from the Geriatrics Ward of Saint Elizabeth's Hospital, Washington, D. C. $\left(\mathrm{O}_{3}\right.$ and $\left.\mathrm{O}_{5}\right)$. These two patients were hospitalized primarily because they had no one to care for them in the community. One of them $\left(\mathrm{O}_{5}\right)$ had physical infirmity, whereas the other $\left(\mathrm{O}_{3}\right)$ was admitted because of mental depression and excessive use of alcohol following his wife's death. Shortly after this patient's participation in the present study he was discharged from the hospital. The clinical impression of well preserved mental function in these five subjects was confirmed during the detailed interviews and by the results of the psychometric tests (Tables I and II).

The nine mentally deteriorated aged subjects were patients hospitalized on the Geriatrics Wards of Saint Elizabeths Hospital. Patients were sought whose hospital diagnosis was chronic brain syndrome and who manifested the characteristic symptoms of this illness, in the absence of focal neurological signs. A loss of memory more marked for recent than remote events was considered the distinguishing feature of organic brain disease. Emotional lability, defects in orientation, in comprehension and in judgment frequently accompanied the memory impairment. In addition, an attempt was made to exclude patients with a history of or with present evidence of such stigmata of functional mental illness as delusions, hallucinations, ideas of reference, and depersonalization. The endeavor to meet these ideal criteria in a hospital devoted primarily to the care of committed patients was not entirely successful. Thus one subject $\left(D_{2}\right)$ had a past history of auditory hallucinations and was considered to show minimal signs of residual schizophrenia in addition to organic deficit. Two others $\left(D_{1}\right.$ and $\left.D_{5}\right)$ had vague unsystematized paranoid notions regarding their families; however, both had ade- 
$\mathrm{CMRO}_{2}$ AND MENTAL FUNCTION

TABLE I

Descriptive data for populations tested*

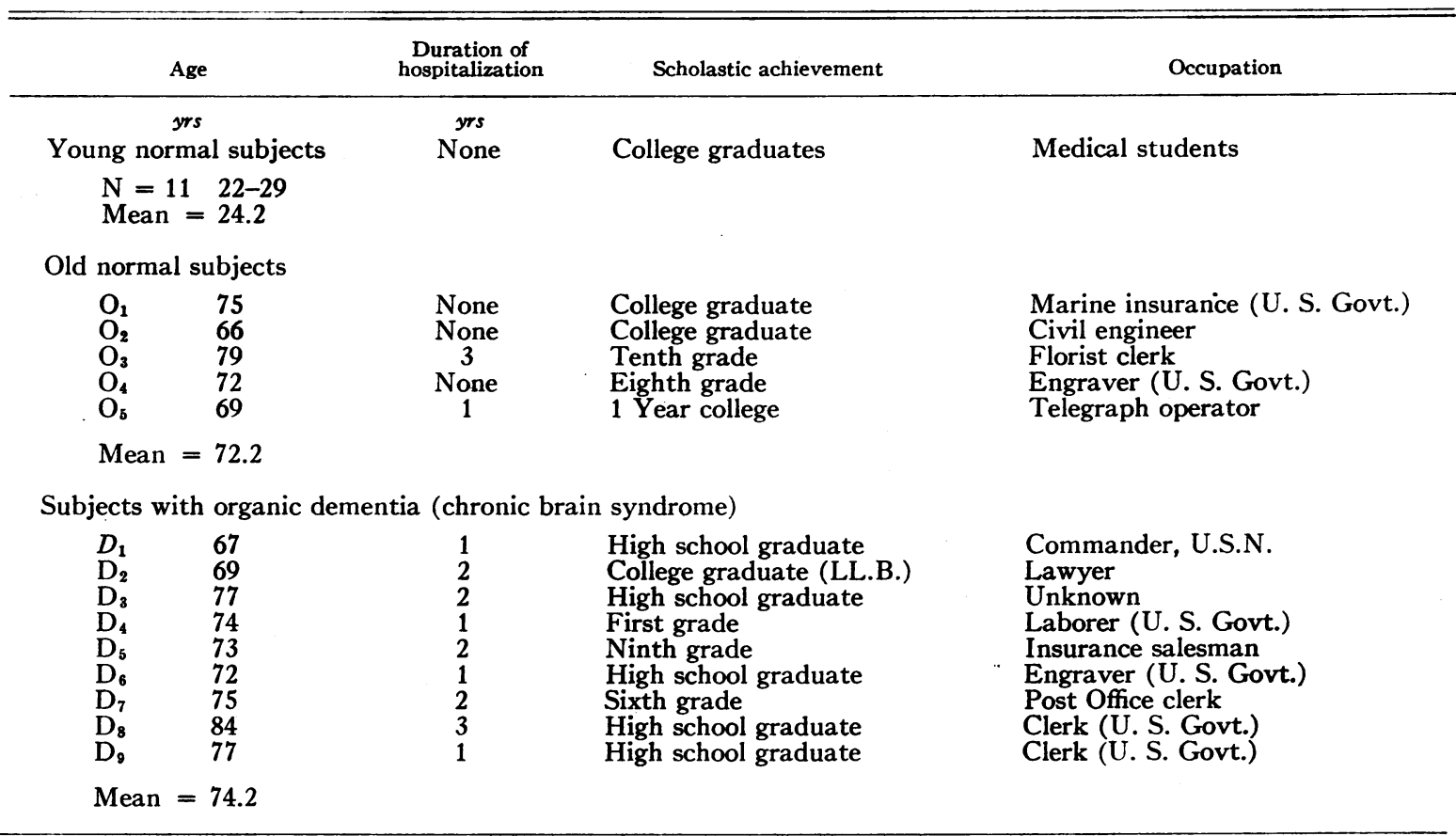

* Positive findings on neurological examination: $\mathrm{D}_{4}$ had moderate Parkinsonism and left homonymous visual field defect; $D_{7}$ had moderate Parkinsonism; and $D_{0}$ had aphasia and apraxia, but no other neurological symptoms or signs.

quate histories of work and family adjustment. Finally, two additional patients presented focal neurological signs (Tables I and II). Although none was capable of managing his affairs outside the hospital, three patients had ground parole privileges. The remaining six subjects were so confused as to require assistance in the simple tasks of everyday life; they were unable to find their way about, to dress themselves, and were usually disoriented in all spheres. Two of the deteriorated subjects, $D_{8}$ and $D_{9}$, were considered to be more severely affected than the others. These two subjects were deliberately chosen in order to include in the study some subjects with an extreme degree of impairment. None of the patients was a behavior problem and all except

TABLE II

Scores on psychometric tests

\begin{tabular}{|c|c|c|c|c|c|c|c|c|c|c|c|}
\hline & \multicolumn{10}{|c|}{ WAIS subtests (standard scores) } & \multirow[b]{2}{*}{$\begin{array}{c}\text { Raven's } \\
\text { matrices* }\end{array}$} \\
\hline & $\begin{array}{c}\text { Informa- } \\
\text { tion }\end{array}$ & $\begin{array}{l}\text { Compre- } \\
\text { hension }\end{array}$ & $\begin{array}{l}\text { Arith- } \\
\text { metic }\end{array}$ & $\underset{\text { ties }}{\text { Similari- }}$ & $\begin{array}{l}\text { Digit } \\
\text { span }\end{array}$ & $\begin{array}{l}\text { Vocabu- } \\
\text { lary }\end{array}$ & $\begin{array}{l}\text { Digit } \\
\text { symbol }\end{array}$ & $\begin{array}{l}\text { Picture } \\
\text { complet. }\end{array}$ & $\begin{array}{c}\text { Block } \\
\text { design }\end{array}$ & $\begin{array}{l}\text { Picture } \\
\text { arrang. }\end{array}$ & \\
\hline $\begin{array}{l}\mathrm{O}_{1} \\
\mathrm{O}_{2} \\
\mathrm{O}_{3} \\
\mathrm{O}_{4} \\
\mathrm{O}_{5} \\
\mathrm{D}_{1} \\
\mathrm{D}_{2} \\
\mathrm{D}_{3} \\
\mathrm{D}_{4} \\
\mathrm{D}_{5} \\
\mathrm{D}_{6} \\
\mathrm{D}_{7} \\
\mathrm{D}_{8} \\
\mathrm{D}_{9}\end{array}$ & $\begin{array}{r}17 \\
19 \\
9 \\
14 \\
16 \\
17 \\
14 \\
13 \\
5 \\
5 \\
9 \\
9 \\
7\end{array}$ & $\begin{array}{r}15 \\
18 \\
10 \\
19 \\
17 \\
18 \\
14 \\
10 \\
7 \\
8 \\
9 \\
6 \\
8\end{array}$ & $\begin{array}{r}11 \\
17 \\
10 \\
13 \\
15 \\
15 \\
13 \\
9 \\
5 \\
10 \\
15 \\
8 \\
4\end{array}$ & $\begin{array}{r}16 \\
1 \\
7 \\
11 \\
11 \\
15 \\
10 \\
12 \\
4 \\
4 \\
8 \\
2 \\
5\end{array}$ & $\begin{array}{r}7 \\
12 \\
7 \\
9 \\
12 \\
14 \\
14 \\
14 \\
6 \\
9 \\
11 \\
1 \\
6 \\
\mathrm{U}\end{array}$ & $\begin{array}{c}17 \\
18 \\
10 \\
15 \\
19 \\
14 \\
17 \\
19 \\
2 \\
11 \\
11 \\
10 \\
9 \\
\text { estable o }\end{array}$ & $\begin{array}{c}7 \\
8 \\
5 \\
8 \\
7 \\
6 \\
7 \\
\text { NT† } \\
0 \\
7 \\
3 \\
\text { NT } \\
\text { NT } \\
\text { all task }\end{array}$ & $\begin{array}{r}12 \\
13 \\
9 \\
12 \\
11 \\
14 \\
9 \\
N T \\
5 \\
6 \\
7 \\
7 \\
\text { NT }\end{array}$ & $\begin{array}{r}8 \\
12 \\
8 \\
12 \\
10 \\
6 \\
7 \\
9 \\
0 \\
9 \\
5 \\
5 \\
\text { NT }\end{array}$ & $\begin{array}{r}7 \\
13 \\
6 \\
7 \\
6 \\
6 \\
7 \\
\text { NT } \\
1 \\
6 \\
5 \\
0 \\
\text { NT }\end{array}$ & $\begin{array}{r}49 \\
64 \\
32 \\
46 \\
59 \\
38 \\
41 \\
\text { NT } \\
0 \\
39 \\
34 \\
24 \\
\text { NT }\end{array}$ \\
\hline
\end{tabular}

* Total items correct on combined children's and adult forms.

† Not tested. 
one, $D_{0}$, were capable of performing at least some psychological tests.

The etiology of the chronic brain syndrome in these patients was obscure. No subject had a history of syphilis, apoplexy, severe cerebral anoxia, trauma, or any of the other usual causes of diffuse cerebral disease. Only two patients presented findings suggestive of cerebral vascular insufficiency, and none suffered from severe arterial hypertension. These facts and the insidious, gradually progressive nature of the mental derangement would seem to argue against a general presumption of vascular ("arteriosclerotic") etiology for cognitive changes observed. The role of cerebral vascular insufficiency cannot, however, be entirely excluded on this basis.

\section{RESULTS}

$C B F$ and $\mathrm{CMRO}_{2}$ in the various clinical groups. Table III lists the unilateral and bilateral CBF and $\mathrm{CMRO}_{2}$ values for each subject, and the means of these values in the three clinical groups.

TABLE III

Bilateral cerebral blood flow and oxygen uptake in 25 subjects

\begin{tabular}{|c|c|c|c|c|c|c|c|c|c|c|c|c|c|}
\hline \multirow[b]{3}{*}{ Subjects } & \multirow[b]{3}{*}{ Age } & \multicolumn{6}{|c|}{10 Minute values* } & \multicolumn{6}{|c|}{ Infinity values* } \\
\hline & & \multicolumn{3}{|c|}{ CBF } & \multicolumn{3}{|c|}{$\mathrm{CMRO}_{2}$} & \multicolumn{3}{|c|}{ CBF } & \multicolumn{3}{|c|}{$\mathrm{CMRO}_{2}$} \\
\hline & & $\mathbf{R}$ & $\mathbf{L}$ & Bil. & $\mathbf{R}$ & $\mathbf{L}$ & Bil. & $\mathbf{R}$ & $\mathbf{L}$ & Bil. & $\mathbf{R}$ & $\mathbf{L}$ & B̀il. \\
\hline
\end{tabular}

I. Young normal subjects

$\begin{array}{clccc}\mathrm{Y}_{1} & 28 & 62.4 & 63.3 & 62.8 \\ \mathrm{Y}_{2} & 29 & 42.2 & 45.0 & 43.6 \\ \mathrm{Y}_{3} & 24 & 52.7 & 65.6 & 58.4 \\ \mathrm{Y}_{4} & 22 & 42.9 & 48.2 & 45.4 \\ \mathrm{Y}_{5} & 23 & 47.7 & 58.2 & 52.4 \\ \mathrm{Y}_{6} & 22 & 49.7 & 46.5 & 48.0 \\ \mathrm{Y}_{7} & 25 & 50.3 & 52.2 & 51.2 \\ \mathrm{Y}_{8} & 28 & 49.0 & 52.2 & 50.5 \\ \mathrm{Y}_{9} & 24 & 54.5 & 61.9 & 58.0 \\ \mathrm{Y}_{10} & 21 & 42.5 & 52.3 & 46.9 \\ \mathrm{Y}_{11} & 24 & 49.4 & 48.8 & 49.1 \\ \text { Mean } \dagger & 24.2 & 48.09 & 53.09 & 50.35 \\ \mathrm{SD} & & 4.29 & 6.78 & 4.91\end{array}$

$\begin{array}{lll}5.45 & 5.20 & 5.33 \\ 3.83 & 4.07 & 3.95 \\ 3.37 & 4.09 & 3.69 \\ 3.35 & 3.80 & 3.56 \\ 3.34 & 4.10 & 3.68 \\ 3.65 & 3.06 & 3.34 \\ 3.75 & 3.64 & 3.70 \\ 3.35 & 3.13 & 3.24 \\ 3.47 & 3.63 & 3.55 \\ 2.72 & 3.53 & 3.08 \\ 3.26 & 2.92 & 3.09 \\ 3.409 & 3.597 & 3.488 \\ 0.310 & 0.439 & 0.289\end{array}$

$\begin{array}{ccc}56.8 & 54.9 & 55.8 \\ 34.5 & 39.4 & 36.8 \\ 44.4 & 57.3 & 50.0 \\ 36.8 & 42.3 & 39.4 \\ 39.5 & 49.7 & 44.0 \\ 43.9 & 42.8 & 43.3 \\ 42.2 & 40.8 & 41.5 \\ 44.0 & 46.8 & 45.4 \\ 44.8 & 47.3 & 46.0 \\ 38.3 & 45.1 & 41.4 \\ 42.0 & 41.5 & 41.7 \\ 41.04 & 45.30 & 42.95 \\ 3.58 & 5.32 & 3.69\end{array}$

$\begin{array}{lll}4.96 & 4.51 & 4.73 \\ 3.13 & 3.57 & 3.33 \\ 2.84 & 3.58 & 3.16 \\ 2.88 & 3.33 & 3.09 \\ 2.77 & 3.50 & 3.09 \\ 3.23 & 2.81 & 3.01 \\ 3.15 & 2.84 & 3.00 \\ 3.01 & 2.81 & 2.91 \\ 2.85 & 2.78 & 2.82 \\ 2.45 & 3.04 & 2.72 \\ 2.77 & 2.49 & 2.62 \\ 2.908 & 3.075 & 2.975 \\ 0.231 & 0.390 & 0.213\end{array}$

II. Old normal subjects

$\begin{array}{clllllll}\mathrm{O}_{1} & 75 & 37.2 & 39.0 & 38.1 & 3.57 & 3.66 & 3.62 \\ \mathrm{O}_{2} & 66 & 45.2 & 53.7 & 49.1 & 2.94 & 3.87 & 3.36 \\ \mathrm{O}_{3} & 79 & 42.2 & 45.6 & 43.8 & 3.15 & 3.34 & 3.24 \\ \mathrm{O}_{4} & 72 & 62.2 & 72.1 & 66.8 & 2.84 & 3.12 & 2.97 \\ \mathrm{O}_{5} & 69 & 59.1 & 48.0 & 53.0 & 3.32 & 2.60 & 2.93 \\ \mathrm{Mean} & \mathbf{7 2 . 2} & 49.18 & 51.68 & \mathbf{5 0 . 1 6} & 3.164 & 3.318 & 3.224 \\ \mathrm{SD} & & 10.91 & 12.57 & 10.86 & 0.293 & 0.494 & 0.286\end{array}$

$\begin{array}{llllll}31.7 & 29.1 & 30.3 & 3.04 & 2.73 & 2.88 \\ 38.0 & 42.8 & 40.3 & 2.47 & 3.08 & 2.76 \\ 35.2 & 38.9 & 37.0 & 2.63 & 2.85 & 2.73 \\ 55.8 & 65.2 & 60.1 & 2.54 & 2.82 & 2.67 \\ 53.1 & 40.6 & 46.0 & 2.98 & 2.20 & 2.54 \\ 42.76 & 43.32 & 42.74 & 2.732 & 2.736 & 2.716 \dagger \\ 10.94 & 13.30 & 11.24 & 0.261 & 0.326 & 0.125\end{array}$

III. Subjects with organic dementia (chronic brain syndrome)

\begin{tabular}{|c|c|c|c|c|c|c|c|c|c|c|c|c|c|}
\hline $\begin{array}{c}\mathrm{D}_{1} \\
\mathrm{D}_{2} \\
\mathrm{D}_{3} \\
\mathrm{D}_{4} \\
\mathrm{D}_{5} \\
\mathrm{D}_{6} \\
\mathrm{D}_{7} \\
\mathrm{D}_{8} \\
\mathrm{D}_{9} \\
\text { Mean } \\
\text { SD }\end{array}$ & $\begin{array}{l}67 \\
69 \\
77 \\
74 \\
73 \\
72 \\
75 \\
84 \\
77 \\
74.2\end{array}$ & $\begin{array}{c}50.7 \\
34.0 \\
34.8 \\
33.8 \\
39.0 \\
58.7 \\
41.0 \\
42.8 \\
32.0 \\
40.76 \\
8.91\end{array}$ & $\begin{array}{c}51.4 \\
39.2 \\
31.5 \\
32.5 \\
34.6 \\
44.0 \\
36.1 \\
36.6 \\
25.9 \\
36.87 \S \\
7.43\end{array}$ & $\begin{array}{c}51.0 \\
36.4 \\
33.1 \\
33.1 \\
36.7 \\
50.3 \\
38.4 \\
39.5 \\
28.6 \\
38.57 \\
7.59\end{array}$ & $\begin{array}{l}3.09 \\
2.87 \\
3.00 \\
3.19 \\
3.01 \\
3.45 \\
3.08 \\
2.63 \\
2.23 \\
2.950 \\
0.350\end{array}$ & $\begin{array}{l}2.89 \\
3.57 \\
2.43 \\
2.54 \\
2.56 \\
2.49 \\
2.65 \\
2.08 \\
1.57 \\
2.531 \S \\
0.543\end{array}$ & $\begin{array}{l}2.99 \\
3.19 \\
2.71 \\
2.85 \\
2.77 \\
2.90 \\
2.85 \\
2.34 \\
1.86 \\
2.718 \S \\
0.395\end{array}$ & $\begin{array}{c}41.1 \\
26.6 \\
32.3 \\
30.6 \\
33.3 \\
51.1 \\
33.3 \\
36.7 \\
23.9 \\
34.32 \\
8.07\end{array}$ & $\begin{array}{c}45.5 \\
30.6 \\
29.1 \\
27.1 \\
32.0 \\
35.3 \\
28.9 \\
30.9 \\
18.9 \\
30.92 \\
7.07\end{array}$ & $\begin{array}{c}43.2 \\
28.5 \\
30.6 \\
28.7 \\
32.6 \\
41.8 \\
30.9 \\
33.6 \\
21.1 \\
32.33 \\
6.79\end{array}$ & $\begin{array}{l}2.51 \\
2.25 \\
2.78 \\
2.89 \\
2.57 \\
3.00 \\
2.50 \\
2.26 \\
1.66 \\
2.491 \\
0.405\end{array}$ & $\begin{array}{l}2.56 \\
2.78 \\
2.25 \\
2.12 \\
2.37 \\
1.99 \\
2.12 \\
1.76 \\
1.15 \\
2.122 \S \\
0.474\end{array}$ & $\begin{array}{l}2.55 \\
2.50 \\
2.50 \\
2.47 \\
2.46 \\
2.41 \\
2.30 \\
1.99 \\
1.37 \\
2.281 \S \\
0.380\end{array}$ \\
\hline \multicolumn{14}{|c|}{ IV. Repeat studies in three subjects with organic dementia } \\
\hline $\begin{array}{l}\mathrm{D}_{2} \text {-II } \\
\mathrm{D}_{2} \text {-III } \\
\mathrm{D}_{5} \text {-II } \\
\mathrm{D}_{7} \text {-II }\end{array}$ & $\begin{array}{l}68 \\
68 \\
73 \\
73\end{array}$ & $\begin{array}{l}40.0 \\
28.5 \\
37.3 \\
41.2\end{array}$ & $\begin{array}{l}41.6 \\
42.9 \\
30.9 \\
39.7\end{array}$ & $\begin{array}{l}40.8 \\
34.2 \\
33.8 \\
40.4\end{array}$ & $\begin{array}{l}3.02 \\
2.16 \\
3.14 \\
2.39\end{array}$ & $\begin{array}{l}3.40 \\
3.91 \\
2.30 \\
2.58\end{array}$ & $\begin{array}{l}3.21 \\
2.86 \\
2.68 \\
2.48\end{array}$ & $\begin{array}{l}33.0 \\
23.1 \\
32.5 \\
31.0\end{array}$ & $\begin{array}{l}30.6 \\
34.8 \\
24.6 \\
30.5\end{array}$ & $\begin{array}{l}31.8 \\
27.8 \\
28.0 \\
30.7\end{array}$ & $\begin{array}{l}2.49 \\
1.75 \\
2.74 \\
1.79\end{array}$ & $\begin{array}{l}2.50 \\
3.17 \\
1.83 \\
1.98\end{array}$ & $\begin{array}{l}2.50 \\
2.32 \\
2.22 \\
1.89\end{array}$ \\
\hline
\end{tabular}

* Values are expressed in cubic centimeters per $100 \mathrm{~g}$ per minute.

$\dagger$ Mean value of subjects $Y_{2}$ to $Y_{11}$ (cf. the text).

$¥$ Significantly lower than in young normal adults $(p<0.05)$.

$\$$ Significantly lower than in old normal subjects $(p<0.05)$. 


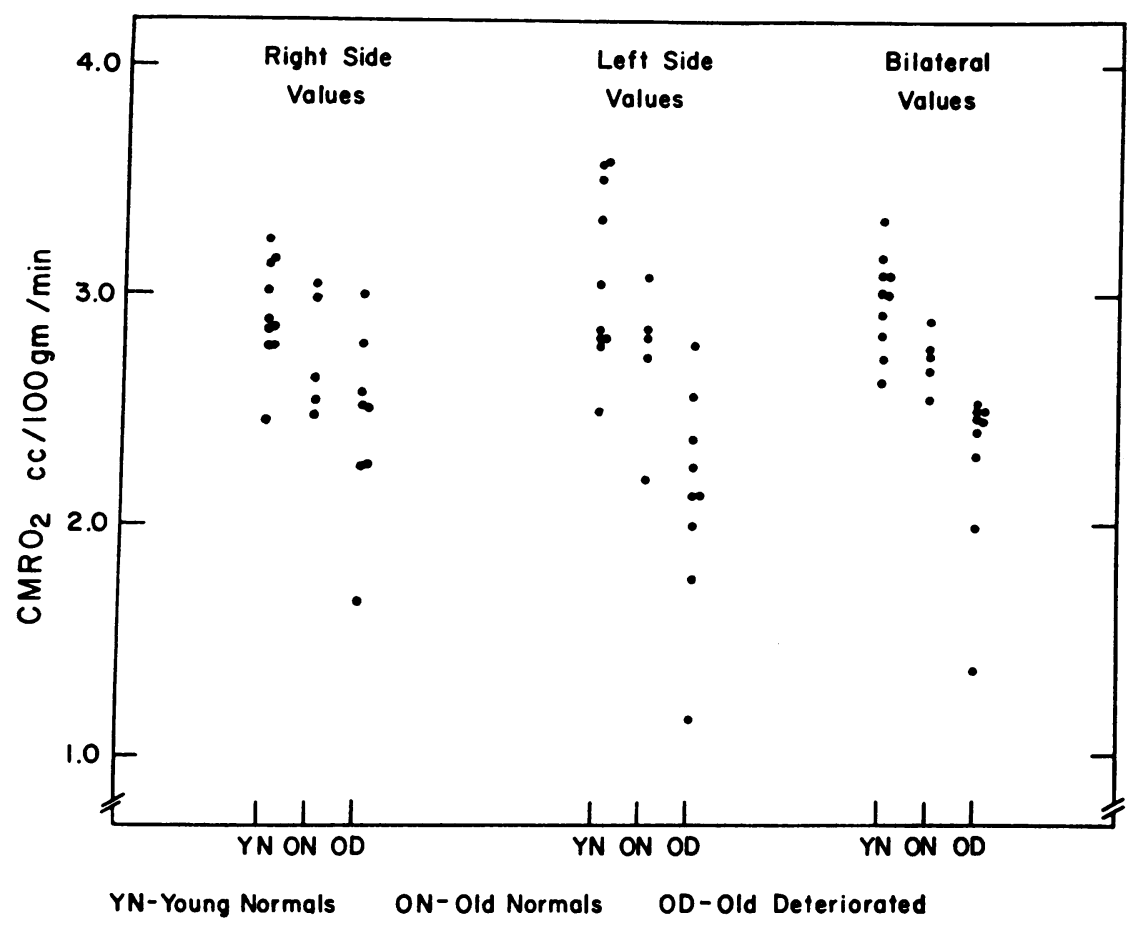

Fig. 2. Scattergram of $\mathrm{CMRO}_{2}$ values in the various clinical groups.

Note that the bilateral values distinguish most sharply among the groups.

The probability levels for the pertinent differences are also indicated. These levels are based on the application of the $t$ test with correction for nonhomogeneous variances (15). ${ }^{1}$ Case $\mathrm{Y}_{1}$ was unusual because the values for $\mathrm{CMRO}_{2}$ were much higher than in any other young normal subject studied. The ratio of the sums of squares in cases $\mathrm{Y}_{2}-\mathrm{Y}_{10} / \mathrm{Y}_{1}-\mathrm{Y}_{11}$ was 0.127 . This ratio (16) indicates that Case $Y_{1}$ differs significantly from the remainder of the cases $(p<0.01)$, and this case has therefore not been included in computation of the mean and standard deviation for the young normal group. The basis of this deviant value was not readily apparent.

Compared with young normal adults, the aged normal subjects showed a significant $(p<0.05)$ reduction of the bilateral $\mathrm{CMRO}_{2}$ value calculated to infinity. In young normals a mean value of $3.0 \mathrm{cc}$ per $100 \mathrm{~g}$ per minute was found as compared to 2.7 in aged normals. The bilateral 10 minute values of $\mathrm{CMRO}_{2}$ were not significantly

1 We wish to thank Dr. Seymour Geisser, Biometrics Section, National Institute of Mental Health, for statistical advice. different at the 5 per cent level of confidence. The unilateral $\mathrm{CBF}$ and $\mathrm{CMRO}_{2}$ values, as well as the bilateral $\mathrm{CBF}$ values, failed to distinguish between these two normal groups at either the 10 minute or infinity values.

The nine aged deteriorated subjects differed significantly from the aged normal controls with respect to several parameters. The bilateral and left side unilateral values for $\mathrm{CMRO}_{2}$ were significantly reduced $(p<0.05)$ in the deteriorated group, whereas the $\mathrm{CMRO}_{2}$ values for the right side were not significantly different. The cerebral blood flow values did not differ significantly in the two groups with the exception of the 10 minute $\mathrm{CBF}$ value on the left side; this was significantly reduced $(p<0.05)$ in the deteriorated subjects. It may also be noted that cases $D_{8}$ and $\mathrm{D}_{9}$, who clinically appeared most deteriorated, also had the lowest $\mathrm{CMRO}_{2}$ values.

In the present study, the bilateral $\mathrm{CMRO}_{2}$ values provide a more clear-cut separation of the clinical groups than do either the right or left side values. This is clearly shown in Figure 2 , in which the three sets of values are plotted for each group. 
TABLE IV

Correlations of cerebral oxygen uptake with psychometric data listed in Table II

\begin{tabular}{lrrrr}
\hline & \multicolumn{4}{c}{$\mathrm{CMRO}_{2}$ (infinity values) } \\
\cline { 2 - 5 } & $\mathrm{N}$ & Right & Left & Bilateral \\
\hline 1. Picture arrangement & 10 & -0.13 & $0.77^{*}$ & $0.71^{*}$ \\
2. Picture completion & 10 & 0.00 & $0.62 \dagger$ & $0.68 \dagger$ \\
3. Digit symbol & 9 & 0.38 & 0.57 & 0.40 \\
"Perception" factor $\ddagger$ & 10 & 0.13 & $0.78^{*}$ & $0.74^{*}$ \\
4. Digit span & 13 & 0.04 & 0.32 & 0.29 \\
5. Arithmetic & 13 & 0.13 & $0.57^{*}$ & $0.57^{*}$ \\
6. Block design & 12 & 0.22 & $0.63 \dagger$ & $0.55 \dagger$ \\
"Immediate memory" & 13 & 0.01 & $0.58 \dagger$ & $0.52 \dagger$ \\
factor $\ddagger$ & & & & \\
7. Similarities & 13 & 0.15 & $0.60 \dagger$ & $0.64 \dagger$ \\
8. Information & 13 & 0.04 & $0.61 \dagger$ & $0.60 \dagger$ \\
9. Vocabulary & 13 & 0.04 & 0.41 & 0.44 \\
"Verbal" factor $\ddagger$ & 13 & 0.08 & $0.59 \dagger$ & $0.59 \dagger$ \\
Raven's matrices & 10 & 0.18 & 0.44 & $0.56 \dagger$
\end{tabular}

* One-tailed test, $\mathrm{p}<0.01$.

† One-tailed test, $\mathrm{p}<0.05$.

$\ddagger$ Based on combining weighted scores of the three preceding subtests. For the "perception" factor, $\mathrm{D}_{7}$ was prorated for Test 3 on the basis of Tests 1 and 2 ; for the "immediate memory" factor, $\mathrm{D}_{8}$ was prorated for Test 6 on the basis of Tests 4 and 5 .

$C B F$ and $C M R O_{2}$ compared with psychometric data. Table IV lists correlation coefficients and their levels of significance calculated from the extrapolated $\mathrm{CMRO}_{2}$ values and the psychometric data of the aged normal and the aged deteriorated group. The raw scores were correlated for individual subtests of the WAIS. The three factors isolated from the Wechsler-Bellevue Scale by Birren (17) among aged subjects were correlated by combining weighted scores of the WAIS subtests. $D_{9}$ was untestable and was not included in any computations. $\mathrm{D}_{3}, \mathrm{D}_{4}$ and $\mathrm{D}_{8}$ did not complete every test $\left(D_{3}\right.$ and $D_{3}$ because of impaired vision, and $\mathrm{D}_{4}$ because of transient uncooperativeness). The N's for the various correlations therefore vary. It will be seen that there are high and significant correlations between $\mathrm{CMRO}_{2}$ values on the left side and the psychometric data. The correlations between bilateral $\mathrm{CMRO}_{2}$ and the psychometric data were of a similar value and significance. None of the correlations for the right side reaches significance and they are all close to zero. Calculations using the $\mathrm{CMRO}_{2}$ values corresponding to an experimental duration of 10 minutes showed much the same results. The cerebral blood flow showed a distinctly lower degree of correlation with the psychometric data than did $\mathrm{CMRO}_{2}$.
DISCUSSION

In young normal adults, the average cerebral blood flow was $50 \mathrm{cc}$ per $100 \mathrm{~g}$ per minute, and the cerebral oxygen uptake was $3.5 \mathrm{cc}$ per $100 \mathrm{~g}$ per minute, when calculated to 10 minutes of inert gas inhalation. These values are similar to those reported by investigators using the nitrous oxide method $(9,18-22)$. The extrapolated values, however, are somewhat lower with average values of $43 \mathrm{cc}$ per $100 \mathrm{~g}$ per minute for cerebral blood flow and $3.0 \mathrm{cc}$ per $100 \mathrm{~g}$ per minute for cerebral oxygen uptake.

As is evident from Table III, extrapolation caused a drop in calculated cerebral perfusion in all studies in normal subjects as well as in patients with organic dementia. An average decrease of about 15 to 20 per cent occurred, with subjects of lower perfusion showing the greater relative decrease. This decrease does not reflect a change in true cerebral perfusion since all studies were carried out in the steady state. Moreover, in all studies the cerebral venous oxygen saturation was measured on an additional blood sample collected at about the eleventh minute of inert gas inhalation; in no case was a marked change (decrease) noted when this value was compared to that obtained from the sample collected at about the fourth minute. Since the decrease in calculated cerebral perfusion value with increasing experimental duration is unrelated to changes in cerebral perfusion, it must be attributed directly to the method of study-the inert gas method.

The theory of inert gas uptake at the tissues, as reviewed by Kety (23), enables us to understand this decrease. Declining values during an experiment carried out in the steady state stem from differences of inert gas uptake rates within the organ studied. Animal studies by Kety et al. (24) indicate that the white matter of the brain has a much lower perfusion rate than does the grey matter, and consequently has a slower gas uptake rate. Therefore, the brain itself may be the source of the observed heterogeneity of $\mathrm{Kr}^{85}$ uptake. Extracerebral contamination of internal jugular blood would also be expected to result in heterogeneous inert gas uptake. This contamination is probably of the order of only a few per cent in the average case (25). Hence, it can- 
not readily account for the 15 to 20 per cent drop in calculated perfusion rate produced by extrapolation.

Whatever the origin of the observed unevenness of tissue $\mathrm{Kr}^{85}$ uptake, only extrapolation can give a theoretically valid estimate of the blood flow of the tissues. The extrapolation, however, must be correct, i.e., it must comprise the saturation characteristics of all tissues not yet saturated at the end of the experiment at 16 minutes of inert gas inhalation. The procedure we employ undoubtedly corrects to some extent the erroneously high 10 minute values due to uneven perfusion and the resultant difference between the average inert gas tension of the tissues and the jugular blood. Therefore, the extrapolated values will approximate more closely the "true" blood flow. But since it is possible that not all slowly saturating tissues have been adequately represented by the present technique of extrapolation, the values derived can only approximate this ideal. Moreover, extrapolation increases the random experimental error of the method. Thus it may be said that the values determined on the basis of an experimental duration of 10 or $16 \mathrm{~min}$ utes are more reliable than extrapolated ones, even though the latter give more valid estimates of true blood flow. In the following discussion both 10 minute and infinity values are mentioned, no special significance being attached to either. In most cases the same conclusion may be reached when using either set of values. It is worth noticing, however, that in the group of old normal subjects the extrapolated value for cerebral oxygen uptake was significantly reduced $(p<0.05)$, while the reduction of the 10 minute value just fell short of reaching statistical significance $(0.05$ $>p<0.10)$. While this difference may be due to chance it may also reflect the possibility that extrapolation actually gives a better estimate of the parameter sought.

The discussion above implies that in many studies employing an experimental duration of 10 minutes, the normal rate of cerebral blood flow and oxygen uptake has been overestimated by about 15 per cent. The values in subjects with low cerebral perfusion have been overestimated to an even greater extent.

The scatter of cerebral oxygen uptake values in the group of young normal adults is of some theoretical interest. In the present series, the standard deviation of extrapolated bilateral $\mathrm{CMRO}_{2}$ values was $0.2 \mathrm{cc}$ per $100 \mathrm{~g}$ per minute or 7 per cent of the mean $\mathrm{CMRO}_{2}$ of $3.0 \mathrm{cc}$ per $100 \mathrm{~g}$ per minute. The same value was found in a previous study using the same bilateral technique (26). In order to compare this value to that of unilateral series the bilateral standard deviation must be corrected for the greater number of analyses involved, and a factor of $1 / 0.87=1.15$ may appropriately be used (26). The resulting corrected standard deviation of about $0.25 \mathrm{cc}$ per 100 $\mathrm{g}$ per minute is significantly lower than that of about $0.5 \mathrm{cc}$ per $100 \mathrm{~g}$ per minute reported in various unilateral series utilizing both the $\mathrm{Kr}^{85}$ method $(9,26)$, and the nitrous oxide method (18-20). On this basis, it may be concluded that the coefficient of variation of the random experimental error of determining cerebral blood flow and oxygen uptake in normal man is of the order of 7 per cent or less when the present bilateral method is employed. A maximum estimate of the random experimental error may also be obtained from the results of repeated bilateral studies. Combining the results of the three subjects in the present study with five cases reported previously (26), a coefficient of variation of 6 per cent is obtained.

The coefficients of variation mentioned above suggest a remarkable constancy of cerebral oxygen uptake; this parameter varies little when the same subject is studied repeatedly over a period of months. Moreover, in young normal adults no marked inter-individual differences seem to exist.

Before commenting on the results obtained in the two aged groups, it is worth noting that the side-to-side differences of cerebral blood flow and oxygen uptake (average 14 and 19 per cent, respectively) are in agreement with previous findings in bilateral studies (cf. References 1 and 26, and the discussion in 27).

Normal old age. The aged normal subjects had nearly the same average CBF as the young normal subjects, while the average bilateral $\mathrm{CMRO}_{2}$ (infinity value) was 9 per cent lower than in young normal subjects. This decrease of $\mathrm{CMRO}_{2}$ was statistically significant $(\mathrm{p}<0.05)$. Other investigators, using unilateral techniques, have found a moderate $(21,22)$ to severe (3) reduction of $\mathrm{CMRO}_{2}$ with age. However, the criteria of normality adopted in these studies are 
not explicitly stated, and it is possible that the aged groups studied may have included some subjects whom we would have classified as deteriorated.

A study of $\mathrm{CMRO}_{2}$ in young and aged normal subjects was recently completed in this laboratory by Sokoloff (28) and Dastur and associates (29). These investigators found no significant reduction of $\mathrm{CMRO}_{2}$ in their aged group. However, their methods differed in that they used the unilateral $\mathrm{N}_{2} \mathrm{O}$ technique without extrapolation, and their criteria of normality were more stringent than our own. (They would have rejected $\mathrm{O}_{3}$ and $\mathrm{O}_{5}$ solely on the basis of having been hospitalized.) For these reasons, this study cannot be directly compared with the present report.

Considering our own findings in the light of the evidence available in the literature, we would suggest that a small but definite reduction in $\mathrm{CMRO}_{2}$ per $100 \mathrm{~g}$ of brain tissue occurs in normal persons of age 70 or more. A reduction in brain weight, not measurable with the present technique, would produce a still greater reduction in total cerebral oxygen uptake. We would further suggest that this reduction in $\mathrm{CMRO}_{2}$ represents a physiological correlate of the well established decline in intellectual function with advanced age. Four out of five of the present group of aged normal subjects spontaneously reported recent changes in their intellectual function, primarily difficulties in remembering names and recent events. While such changes cannot be demonstrated with the tests employed, they are nevertheless quite real and are consistent with the interpretation of a mild degree of chronic brain syndrome or, perhaps, "incipient dementia."

The pathoanatomical basis of the metabolic and mental deterioration in advanced age is presumed to be a degenerative process which diffusely involves the cerebral cortex (cortical atrophy). This interpretation is consonant with the reduction in $\mathrm{CMRO}_{2}$ (see the discussion in Reference 8). While these interpretations are by no means novel, what is new is the suggestion that $\mathrm{CMRO}_{2}$ may represent an objective and quantitative measure of certain major cerebral changes in old age.

Organic dementia. The patients with organic dementia had bilateral cerebral oxygen uptake values which were markedly lower than those found in young normal subjects. The separation of the demented subjects from the aged normal control subjects was not as sharp; however, the latter may be considered to be cases of borderline chronic brain syndrome according to the above discussion. The various observations in the group of mentally deteriorated patients gave no indication of the etiology of the presumably degenerative cerebral affliction causing the fully developed chronic cerebral syndromes. As noted in the description of the patient material, no clinical clues existed either. There was, in particular, no reason to suspect cerebral vascular disease to be of general etiological importance. For a more extensive discussion of the etiological role of cerebral arteriosclerosis in organic dementia the reader is referred to a recent review (27). Thus it is possible that the group of senile demented patients were actually suffering from cerebral involutive processes of the same nature. but of more pronounced intensity, as those occurring in normal old age.

Disregarding etiological considerations, however, there seems to be no reason to emphasize the age of the mentally deteriorated subjects. The results obtained by Lassen, Munck and Tottey (8) in a group of middle-aged demented subjects of average age 55 years (range 42 to 64 years) are very similar to those obtained in the present group of senile patients of average age 74 years (range 67 to 84 years). Thus both studies found severe mental impairment associated with a 40 per cent reduction in cerebral oxygen uptake, whereas less pronounced degrees of dementia were associated with a 20 per cent reduction in cerebral oxygen uptake. It is likely that a reduction in brain weight occurred in many of the patients in both studies, reducing total cerebral oxygen uptake even more than is indicated by the inert gas studies.

The fairly close correlation between degree of dementia and reduction of the average rate of cerebral oxygen uptake of the whole brain suggests that intellectual processes involve the function of large parts of the hemispheres. When correlating the $\mathrm{CMRO}_{2}$ to the raw scores of the psychometric tests, the unilateral values on the left side showed as high a correlation as the bilateral values, whereas no significant correlation was noted with the unilateral values of the right 
side. This finding is presented more extensively elsewhere (30). It may signify some degree of gross localization of cognitive function, so that a left-sided cerebral lesion is of greater consequence for the development of dementia than is a comparable right-sided lesion.

\section{SUM M ARY}

Cerebral oxygen uptake was determined in 11 young normal adults, 5 aged normal subjects, and 9 aged subjects suffering from organic dementia. The bilateral $\mathrm{Kr}^{85}$ modification of the inert gas method was employed. Mental function was assessed in the two aged groups by means of psychiatric interview and psychometric tests. The following results were obtained:

1. In the young normal adults the cerebral oxygen uptake was in average $3.5 \mathrm{cc} \mathrm{O}_{2}$ per $100 \mathrm{~g}$ of brain per minute when the values were calculated corresponding to 10 minutes of inert gas inhalation. This result is in agreement with the findings of previous investigators. However, employing extrapolation to infinity, a mean value of $3.0 \mathrm{cc} \mathrm{O}_{2}$ per $100 \mathrm{~g}$ per minute was found. Similar differences between 10 minute and extrapolated values were found in the two aged groups. The causes of these differences were discussed.

2. The aged normal subjects had an average age of 72 years and an average cerebral oxygen uptake which was 9 per cent below the level in young normal subjects $(p<0.05)$. This small reduction in cerebral oxygen uptake is considered to be a metabolic manifestation of an incipient degenerative cerebral disorder whose functional expression is the decline in mental function in normal subjects with advanced age.

3 . The nine subjects with organic dementia (average age 74 years) had a cerebral oxygen uptake which was significantly reduced below the level in the young and aged control groups. The two subjects with the greatest degree of mental impairment also had the lowest values for cerebral oxygen uptake-values about 40 per cent below the level in young normal adults. The seven subjects with less severe mental defects had a more moderate reduction in cerebral oxygen uptake-in average, about 20 per cent below the level in young normal adults.

4. The reduction of cerebral oxygen uptake is considered to be a rough quantitative measure of cerebral degenerative lesion revealed functionally by the dementia.

\section{ACKNOWLEDGMENT}

This study was carried out at Saint Elizabeths Hospital. The authors are indebted to Dr. Winfred Overholser, Superintendent of Saint Elizabeths Hospital, for making available the necessary facilities. We are also grateful to Drs. Theodore T. Fong and Isabelle Schaffner of the Geriatrics Service, and to Dr. Otis R. Farley, Chief of the Medical Service, for their kind cooperation.

\section{REFERENCES}

1. Kety, S. S., and Schmidt, C. F. The determination of cerebral blood flow in man by the use of nitrous oxide in low concentrations. Amer. J. Physiol. 1945, 143, 53.

2. Freyhan, F. A., Woodford, R. B., and Kety, S. S. Cerebral blood flow and metabolism in psychoses of senility. J. nerv. ment. Dis. 1951, 113, 449.

3. Fazekas, J. F., Alman, R. W., and Bessman, A. N. Cerebral physiology of the aged. Amer. J. med. Sci. 1952, 223, 245.

4. Fazekas, J. F., Bessman, A. N., Cotsonas, N. J., Jr., and Alman, R. W. Cerebral hemodynamics in cerebral arteriosclerosis. J. Geront. 1953, 8, 137.

5. Garfunkel, J. M., Baird, H. W., III, and Ziegler, J. The relationship of oxygen consumption to cerebral functional activity. J. Pediat. 1954, 44, 64.

6. Linden, L. The effect of stellate ganglion block on cerebral circulation in cerebrosvascular accidents. Acta med. scand. 1955, 151, suppl. 301.

7. Patterson, J. L., Jr., Heyman, A., and Nichols, F. T., Jr. Cerebral blood flow and oxygen consumption in neurosyphilis. J. clin. Invest. 1950, 29, 1327.

8. Lassen, N. A., Munck, O., and Tottey, E. R. Mental function and cerebral oxygen consumption in organic dementia. A. M. A. Arch. Neurol. Psychiat. 1957, 77, 126.

9. Lassen, N. A., and Munck, O. The cerebral blood flow in man determined by the use of radioactive krypton. Acta physiol. scand. 1955, 33, 30.

10. Deibler, G. E., Holmes, M. S., Campbell, P. L., and Gans, J. The use of triton $\mathrm{X}-100$ as a hemolytic agent in the spectrophotometric measurement of blood $\mathrm{O}_{2}$ saturation. J. appl. Physiol. 1959, 14, 133.

11. Van Slyke, D. D., and Neill, J. M. The determination of gases in blood and other solutions by vacuum extraction and manometric measurement. J. biol. Chem. 1924, 61, 523.

12. Wechsler, D. Manual for the Wechsler Adult Intelligence Scale. New York, Psychological Corporation, 1955.

13. Raven, J. C. Progressive Matrices (1938) and coloured progressive matrices. London, H. K. Lewis \& Co., 1956. 
14. Bender, L. A visual motor Gestalt test and its clinical use. N. Y. The American Orthopsychiatric Association, Inc., 1938, Res. monog. no. 3.

15. Welch, B. L. On the comparison of several mean values: An alternative approach. Biometrika 1951, 38,330 .

16. Grubbs, F. E. Sample criteria for testing outlying observations. Ann. math. Stat. 1950, 21, 27.

17. Birren, J. E. A factorial analysis of the WechslerBellevue scale given to an elderly population. J. cons. Psychol. 1952, 16, 399.

18. Kety, S. S., and Schmidt, C. F. The nitrous oxide method for the quantitative determination of cerebral blood flow in man: Theory, procedure and normal values. J. clin. Invest. 1948, 27, 476.

19. Scheinberg, P., and Stead, E. H., Jr. The cerebral blood flow in male subjects as measured by the nitrous oxide technique. Normal values for blood flow, oxygen utilization, glucose utilization and peripheral resistance, with observations on effect of tilting and anxiety. J. clin. Invest. 1949, 28, 1163.

20. Bernsmeier, A., and Siemons, K. Die Messung der Hirndurchblutung mit der Stickoxydulmethode. Pflüg. Arch. ges. Physiol. 1953, 258, 149.

21. Scheinberg, P., Blackburn, I., Rich, M., and Saslaw, M. Effects of aging on cerebral circulation and metabolism. A.M.A. Arch. Neurol. Psychiat. 1953, $70,77$.
22. Schieve, J. F., and Wilson, W. P. The influence of age, anesthesia and cerebral arteriosclerosis on cerebral vascular activity to $\mathrm{CO}_{2}$. Amer. J. Med. 1953, 15, 171.

23. Kety, S. S. The theory and applications of the exchange of inert gas at the lungs and tissues. Pharmacol. Rev. 1951, 3, 1.

24. Kety, S. S. in The Control of the Circulation of the Blood, R. J. S. McDowell, Ed. London, Wm. Dawson \& Sons, Ltd., 1956, p. 176.

25. Shenkin, H. A., Harmel, M. H., and Kety, S. S. Dynamic anatomy of the cerebral circulation. A. M. A. Arch. Neurol. Psychiat. 1948, 60, 240.

26. Munck, O., and Lassen, N. A. Bilateral cerebral blood flow and oxygen consumption in man by use of krypton 85. Circulat. Res. 1957, 5, 163.

27. Lassen, N. A. Cerebral blood flow and oxygen consumption in man. Physiol. Rev. 1959, 39, 183.

28. Sokoloff, L. Circulation and metabolism of the brain in relation to the process of aging in The Process of Aging in the Nervous System, J. E. Birren, H. A. Imus, W. F. Windle, Eds. Springfield, I1l., Charles C Thomas, 1959, pp. 113-126.

29. Dastur, D. K., Hansen, D. B., Lane, M. H., Butler, R. B., Perlin, S., and Sokoloff, L. Unpublished data.

30. Feinberg, I., Lane, M., and Lassen, N. A. In preparation.

\section{CORRECTION}

Through an error in the editorial office, on page 2052 of the paper, "Chronic Progressive Myopathy with Myoglobinuria: Demonstration of a Glycogenolytic Defect in the Muscle," by Rudi Schmid and Robert Mahler (J. clin. Invest. 1959, 38, 2044), PAS, periodic acid-Schiff reaction, was incorrectly defined as paraaminosalicylic acid. 